\title{
BMJ Open Criminality and suicide: a longitudinal Swedish cohort study
}

\author{
M Stenbacka, ${ }^{1,2}$ A Romelsjö, ${ }^{2} \mathrm{~J}$ Jokinen $^{3}$
}

To cite: Stenbacka M, Romelsjö A, Jokinen J. Criminality and suicide: a longitudinal Swedish cohort study. BMJ Open 2014;4: e003497. doi:10.1136/ bmjopen-2013-003497

- Prepublication history for this paper is available online. To view these files please visit the journal online (http://dx.doi.org/10.1136/ bmjopen-2013-003497)

Received 1 July 2013

Revised 19 November 2013 Accepted 20 November 2013

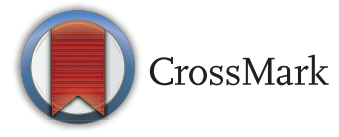

${ }^{1}$ Addiction Center Stockholm, St Eriks Hospital, Stockholm, Sweden

${ }^{2}$ Department of Public Health Sciences, Karolinska Institute, Stockholm, Sweden

${ }^{3}$ Department of Clinical Neuroscience, Karolinska Institute, Karolinska University Hospital, Stockholm, Sweden

Correspondence to Dr M Stenbacka; marlene.stenbacka@ki.se

\section{ABSTRACT}

Objectives: This study aimed to investigate whether violent and non-violent offending were related to elevated risk of suicide. We also investigated whether the risk was higher among those with repeated offences and how experiences of substance misuse and suicide attempt modified the relationship.

Design: A nationwide prospective cohort study. Setting: A register study of 48834 conscripted men in 1969/1970 in Sweden followed up during a 35-year period in official registers.

Participants: A birth cohort of 48834 men who were mandatory conscripted for military service in 1969/70 at the age of 18-20 years. Possible confounders were retrieved from psychological assessments at conscription and the cohort was linked to mortality and hospitalisation and crime records from 1970 onwards. Estimates of suicide risks were calculated as HR with $95 \%$ Cls using Cox proportional regression analyses with adjustment for potential confounding by family, psychological and behavioural factors including substance use and psychiatric disorders.

Results: Of the total cohort, 2671 (5.5\%) persons died during the follow-up period. Of these, $615(23 \%)$ persons died due to suicide. Non-violent criminality was evident for $29 \%$ and violent criminality for $4.7 \%$ of all the participants. In the crude model, the violent offenders had nearly five times higher risk (HR=4.69, 3.56 to 6.19 ) to die from suicide and non-violent criminals had about two times higher risk ( $H R=2.08$, 1.72 to 2.52 ). In the fully adjusted model, the HRs were still significant for suicide in the non-violent group. Conclusions: Experiences of violent or non-violent criminality were associated with increased risk of suicide. Comorbidity with alcohol and substance use and psychiatric disorders modified the risk, but the suicide risk remained significantly elevated for nonviolent criminals. It is crucial to identify offenders and especially repeated offenders who also suffer from alcohol or substance misuse and psychiatric illness in clinical settings in order to prevent suicide.

\section{INTRODUCTION}

Almost one million people worldwide die from suicide every year. Suicide was accounted for $1.8 \%$ of the total disease burden in 1998 and has been estimated to be $2.4 \%$ by $2020 .{ }^{12}$ Furthermore, suicide is one

\section{Strengths and limitations of this study}

- The study is based on a large national cohort with a longitudinal design and with several adolescent confounders. Only a small part, $2-3 \%$ of the participants, was excluded from the study mainly because of physical or psychiatric disorder/disability.

- This study adds knowledge about the association between violent and non-violent criminality and the risk of suicide.

- The limitations were that non-anonymous questionnaires were used, which may have contributed to a lower response rate of especially problematic issues such as alcohol and substance use, but the response rate was nevertheless high.

of the three leading causes of mortality in the age category 15-44 years and the second among those aged $15-19 .^{3}$

Earlier studies on the relationship between criminality and suicide have been mostly conducted on populations in prison or newly released from prison. ${ }^{4-7}$ Studies have found an elevated risk of 5-9, and in some studies much higher depending on the age group for suicide among prison inmates compared with the general population, and more than one-third of the male suicide cases had a history of criminality. ${ }^{6} 7$

Studies of suicide among offenders who are not in prisons are rather few, but an elevated risk in this population has also been reported. ${ }^{8}{ }^{9}$ Webb et at examined suicide risk among people processed by the Danish criminal justice system in a nested casecontrol study of 27219 suicide cases and 524899 matched living controls over three decades. More than one-third of the male cases had a criminal history and when compared with the general population, custodial sentence, psychiatric treatment and violent offences were important predictors for suicide. $^{6}$

In a Swedish national cohort study of 992881 young adults, it was found that female and male repeated offenders had a 
suicide risk of about six times higher than nonoffenders. ${ }^{10}$ Young female offenders had a risk of 3.7 and young male offenders had a risk of 3.0 after control for psychiatric inpatient care and for substance misuse until the end of the follow-up. ${ }^{10}$

A suicide attempt has been considered as the strongest predictor of the subsequent suicide. The suicide risk after an attempt was up to 40 times the expected rate ${ }^{11}$ and lifetime prevalence suicide rates of suicide attempters with the severe coexistent psychiatric disorder were even higher. ${ }^{12}$

In a Swedish national register-based study, it was found that patients who had attempted suicide by hanging evidenced the highest risk for suicide in 1 year after the attempt. $^{13}$

Studies on risk factors for suicide have stressed the importance of substance misuse for elevated mortality rates. ${ }^{1415}$ In most of the studies, suicide is far more prevalent in substance users than in the general population. For instance, Darke et $a l^{16}$ found that about one-third of the substance misusers had experiences of suicide attempts. Suicide among opioid misuses has been estimated to be 14 times higher than the general population. ${ }^{11} 17$ Furthermore, one-fifth or more of the suicide cases had substances presented in the blood in one study. ${ }^{16}$

A previous study on the Swedish conscripts with a 13-year follow-up revealed that social and behavioural factors and neurotic and personality disorder measured at conscription were most significantly associated with a high rate of suicide. ${ }^{18}$ Likewise, a longitudinal study of offenders and victims of violence and cause-specific mortality showed that HR for suicide risk was about two after adjustment for various psychosocial confounders. ${ }^{14}$

In this representative, nationwide, general population study, we followed 48834 Swedish conscripts during 35 years, in order to examine whether violent and nonviolent offending were related to elevated risk of suicide. We also investigated whether the risk was higher among those with repeated offences and how substance misuse and suicide attempt history modified the relationship. Moreover, we studied the choice of suicide methods for the violent and non-violent criminal groups.

This study aimed to address four main research questions.

1. Do conscripts with violent or non-violent criminality offences differ with respect to risk of suicide?

2. Does suicide risk increase with repeated offences?

3. Does a history of previous suicide attempt and/or serious substance and alcohol misuse modify the relationship between violent and non-violent criminality on suicide?

4. Do methods of suicide differ between the criminal groups?

\section{MATERIALS AND METHODS Participants}

This nationwide study is based on 48834 Swedish men aged 18-20 years conscripted for military service from 1
July 1969 to 30 June 1970 . About 2-3\% was exempted from the military service mainly because of a physical or psychiatric disorder/disability. In order to get a homogenous age group, we included 48411 conscripts born 1949-1951. Six per cent of the conscripts were born in $1949,17 \%$ in 1950 and $75 \%$ in 1951 out of total 50063 conscripts. The mean age at the end of the follow-up was about 53 years of age for the survivors.

\section{Measures}

\section{Measurement of potential confounders}

At conscription, each conscript was asked to answer two non-anonymous voluntary questionnaires. The first included questions about family and psychosocial background and health. The second about substance use including alcohol and drug use and sniffing of solvents. Studies have shown that the questionnaires have been found to have sufficient validity for epidemiological studies. $^{18} 19$

Besides the measures of substance use, the confounders were selected from the conscription data, based on the scientific studies and earlier studies of this cohort. ${ }^{10} 14$ 19-22

The confounders were: (1) father's occupation: social class I+II versus social class III. Social class I includes proprietors, private entrepreneurs and high-salaried employees in private entrepreneurs and high-income employees in private and public sectors; social class II includes other incomes and small entrepreneurs and social class III mainly blue-collar workers. ${ }^{23}$ (2) Medication for nervous problems among parents or other members in the family (yes, at least one parent or family member vs no). (3) Conduct problems at school (at least once vs no). (4) Any prior contact with police and juvenile authorities (yes at least once vs no). (5) Having taken medication for psychiatric disorder (at least once vs no).

The psychological variables were: emotional control and intellectual capacity were assessed by trained military psychologist who performed a structured interview with all conscripts. The psychologists used questionnaire and interview data and the measures were assessed on a five-point Likert scale. The ratings were regularly checked for interrater reliability, which was satisfactory. ${ }^{24}$ If the psychologist discovered or the conscript reported any psychiatric disorder, the participant was referred to a psychiatrist and an eventual diagnosis was coded according to ICD-eight. ${ }^{18}{ }^{24}$ Details of this procedure and the validity of the assessments have been described earlier. ${ }^{18} 24-26$

Intellectual capacity was based on four main intellectual and cognitive tests, measuring verbal, logical-inductive, spatial and technical and mechanical ability. The results of the tests were aggregated in a fivepoint summary score for overall intelligence, as described in detail by Ståhlberg ${ }^{27}$ and David et al. ${ }^{28}$ These scale of IQ was scored $1=$ very bad; $2=$ bad; $3=\bmod$ erate; $4=$ good; $5=$ very good and expressed as intelligence 
(1-3 vs $4-5)$. Details of this procedure and the validity of the assessments have been described by Otto. ${ }^{24}$

Problematic alcohol use was dichotomised (yes vs no, with yes defined as one or more of consumption of $\geq 210 \mathrm{~g}$ pure alcohol per week, having ever taken an 'eyeopener', being intoxicated often, having been taking into custody for public drunkenness on at least one occasion and non-prescription drug (ever vs never). Drug misuse was coded (yes vs no), with yes defined as used illicit drugs 10 times or more or any intravenous drug use.

\section{Measures of alcohol and drug misuse and suicide attempt}

Data from the National Swedish inpatient register were used to identify inpatient care with an alcohol or drug diagnosis of dependence or misuse according to ICD-8 and ICD-9 from 1987 and ICD-10 from 1997 onwards.

The register includes details concerning inpatient care stays and days at hospital and diagnoses, and has covered all public hospitals in Stockholm and Uppsala County since 1972, 85\% of all Swedish public inpatient care stays since 1983 and about 98-99\% since 1987. The ICD classifications for hospitalisation and mortality were: Drug misuse-ICD-8: 304 and 965.0; ICD-9: 304, 965A, 968F, 969G and 969H; and ICD-10: F11-12, F14, F15, F16, F18, F19, O35.5, P04.4, T40.0-T40.3, T40.5-T40.9, T43.6, Z71.5 and X42. Alcohol misuse-ICD-8: 291, 303, 571.00, 571.01 and 980; ICD-9: 291, 303, 305A, 357F, 425F, 535D, 571A-571D and 980; and ICD-10: E24.4, F10, G31.2, G62.1, G72.1, I42.6, K29.2, K70, K86.0, O35.4, P04.3, Q86.0, T51, X45, Y91, Z50.2 and Z71.4. Suicide attempt-ICD-8 and ICD-9. Determined suicide attempt-E950-E959 and undetermined E980-E989: ICD-10. Determined X60-X84 and undetermined suicide attempt: Y10-Y34.

\section{Suicide}

Information about suicide was obtained from Cause of Death Register which provides mortality data and covers more than $99 \%$ of all deaths occurring in Sweden and is based on information from death certificates. Suicide was classified according to ICD-8 and ICD-9: E950-E959 and ICD-10: X60-X84 or as death with undetermined intent ICD-8 and ICD-9: E980-E989 and ICD-10: Y10-Y34. The same ICD codes as for the hospital register.

\section{Measurement of crime}

Data from the National Crime Register were used to identify date, type and number of criminal offences. The Crime Register contains information on all convictions in Sweden from 1966 and onwards. Criminality was divided into three categories: no crime, violent crime and non-violent crime. Violence was defined as: homicide, manslaughter and assault and non-violent crime all the other convictions. We also categorised the cohort according to the number of crimes meaning for violent and non-violent offenders ( 0,1 and 2 or more crimes).
Information about alcohol and drug inpatient care, criminality and suicide was linked at Statistics Sweden (Statistiska Centralbyrån) via the unique personal number for each individual in the cohort. This personal number was then replaced with an individual serial number making the data anonymous to the research group, after approval of the Regional ethical review board in Stockholm.

\section{Statistical analyses}

Cox proportional bivariate and multivariate regression analysis were used to calculate HRs with 95\% CIs for violent and non-violent criminality and suicide. We adjusted for confounders measured at conscription in relation to time to suicide. The surveillance time was calculated from September 1969 until death or until 31 December 2004 for all participants in the cohort.

We had no exact information whether a person had emigrated from Sweden or not during the follow-up period, therefore we could not censor for emigration in the calculation of person time. In order to investigate the association between the number of criminal offences and mortality, we categorised participants according to committed numbers of offences $(0,1,2$ and more) in relation to the time to suicide by using Cox proportional regression analysis. The independent variables were measured only once that why the time order was difficult to prove. Some of these variables like alcohol-or substance use could act as confounders or mediators on criminality and suicide.

A test of the proportional hazard assumption was performed for each confounder (X) in bivariate and multivariate analyses by using a time-dependent explanatory variable in the model $\left(\mathrm{X}^{*}(\log\right.$ time-average value of the $\log$ time $))$. If the $p$ value was significant $(p<0.05)$ the proportional hazard assumption was not fulfilled and the variable was not included in the analyses.

We used Kaplan-Meier survival curves to plot survival probability of suicide in non-criminals, violence and other criminality during the 35-year follow-up.

$\chi^{2}$ Test was used when calculating early confounders and hospitalisation in relation to criminality.

\section{RESULTS}

Of the total cohort, 2671 participants (5.5\%) died during the follow-up period. Of these, 615 (23\%) died due to suicide (474 determined and 141 undetermined). Mortality was more prevalent in the criminal groups: no criminality $(4.11 \%)$, non-violent $(7.3 \%)$ and violent criminality $(13.7 \%)$.

The suicide cases were rather equally distributed throughout the 35-year follow-up period.

More than one-third $(34 \%)$ of the suicide cases were $\leq 30$ years, $30 \%$ of the cases were in the age category $31-$ 40 years and the remaining participants $(36 \%)$ were $\geq 41$ years. The mean age was 36 years.

Table 1 shows the distribution of 11 confounders measured at conscription divided into three groups of 
Table 1 Baseline characteristics and hospitalisation in relation to non-violent and violent criminality

\begin{tabular}{|c|c|c|c|c|}
\hline & No crime & $\begin{array}{l}\text { Non-violent } \\
\text { criminality }\end{array}$ & $\begin{array}{l}\text { Violent } \\
\text { criminality }\end{array}$ & $\chi^{2}$, Probability* \\
\hline \multicolumn{5}{|l|}{ Fathers' social class } \\
\hline III & $15433(47.67)$ & $7146(50.38)$ & $1321(58.07)$ & \\
\hline I-II & $15680(48.43)$ & $6133(43.24)$ & 739 (32.48) & $204.72,<0.0001$ \\
\hline Missingt & $1262(3.90)$ & $904(6.37)$ & $215(9.45)$ & \\
\hline \multicolumn{5}{|c|}{ Medication for nervous problems in the family } \\
\hline Yes (parents or other family members) & $9747(30.11)$ & $4897(34.53)$ & $918(40.35)$ & \\
\hline No & 21698 (67.02) & $8738(61.61)$ & $1231(54.11)$ & $201.34,<0.0001$ \\
\hline Missing & $931(2.88)$ & $548(3.86)$ & $126(5.54)$ & \\
\hline \multicolumn{5}{|l|}{ Conduct problems at school } \\
\hline Yes (at least once) & $5726(17.69)$ & $4743(33.44)$ & $1188(52.22)$ & \\
\hline No & 26352 (81.39) & 9226 (65.05) & $1034(45.45)$ & $2470.41,<0.0001$ \\
\hline Missing & $298(0.92)$ & $214(1.51)$ & $53(2.33)$ & \\
\hline \multicolumn{5}{|l|}{ Taken medication for psychiatric problems } \\
\hline Yes & $3217(9.94)$ & $1858(13.10)$ & $456(20.04)$ & \\
\hline No & 28821 (89.02) & 12087 (85.22) & $1757(77.23)$ & $29335,<0.0001$ \\
\hline Missing & $338(1.04)$ & $238(1.68)$ & $62(2.73)$ & \\
\hline \multicolumn{5}{|l|}{ Emotional control } \\
\hline Very bad, bad & $8677(26.8)$ & $4941(34.84)$ & 1135 (49.89) & \\
\hline Very good, good, medium & $23471(72.6)$ & 9094 (64.12) & $1097(48.22)$ & $769.81,<0.0001$ \\
\hline Missing & $228(0.70)$ & $148(1.04)$ & $43(1.89)$ & \\
\hline \multicolumn{5}{|l|}{ Intellectual capacity } \\
\hline Below average & $5190(16.03)$ & $3296(23.24)$ & 812 (35.69) & \\
\hline Above average, average & 27145 (83.84) & 10859 (76.56) & $1457(64.04)$ & $764.81,<0.0001$ \\
\hline Missing & $41(0.13)$ & $28(0.20)$ & $6(0.26)$ & \\
\hline \multicolumn{5}{|l|}{ Psychiatric diagnosis (at conscription) } \\
\hline Yes (at least one diagnosis) & 3151 (9.73) & $2251(15.87)$ & $679(29.85)$ & \\
\hline No & 28679 (88.58) & 11639 (82.06) & $1559(68.53)$ & $1008.59,<0.0001$ \\
\hline Missing & $546(1.69)$ & $293(2.07)$ & $37(1.63)$ & \\
\hline \multicolumn{5}{|l|}{ Contact with police and juvenile authorities } \\
\hline Yes (several or some times) & $6726(20.77)$ & $5585(39.38)$ & $1458(64.09)$ & \\
\hline No & $25208(77.86)$ & 8314 (58.62) & 754 (33.14) & $3305.72,<0.0001$ \\
\hline Missing & $442(1.37)$ & $284(2.00)$ & $63(2.77)$ & \\
\hline \multicolumn{5}{|l|}{ Risky alcohol use } \\
\hline Yes & $2683(8.29)$ & 2807 (19.79) & $901(39.60)$ & \\
\hline No & 29279 (90.43) & 11119 (78.40) & $1310(57.58)$ & $2681.86,<0.0001$ \\
\hline Missing & $414(1.28)$ & $257(1.81)$ & $64(2.91)$ & \\
\hline \multicolumn{5}{|l|}{ Dug misuse } \\
\hline Yes & $585(1.81)$ & $919(6.48)$ & 248 (10.9) & \\
\hline No & $30410(94.00)$ & 12533 (88.37) & 1864 (81.93) & $1063,23,<0.0001$ \\
\hline Missing & $1381(4.27)$ & $731(5.15)$ & $163(7.16)$ & \\
\hline \multicolumn{5}{|l|}{ Sniffing } \\
\hline At least once & $3187(9.84)$ & $2614(18.43)$ & $673(29.58)$ & \\
\hline No & $28756(88.82)$ & 11259 (79.38) & $1520(66.81)$ & $1234.54,<0.0001$ \\
\hline Missing & $433(1.34)$ & $310(2.19)$ & $82(3.60)$ & \\
\hline \multicolumn{5}{|l|}{ Hospitalisation } \\
\hline \multicolumn{5}{|l|}{ Alcohol hospitalisation } \\
\hline Yes (at least once) & $571(1.76)$ & $1524(10.75)$ & 727 (31.96) & \\
\hline No & 31805 (98.24) & 12659 (89.25) & $1548(68.04)$ & $4464.28,<0.00001$ \\
\hline \multicolumn{5}{|l|}{ Drug use hospitalisation } \\
\hline Yes (at least once) & $50,(0.15)$ & $352(2.48)$ & 265 (11.65) & \\
\hline No & 32326 (99.85) & $13831(97.52)$ & 2010 (88.35) & $2269.25,<0.00001$ \\
\hline \multicolumn{5}{|l|}{ Hospitalisation for suicide attempts } \\
\hline Yes (at least once) & $303(0.94)$ & $581(4.10)$ & $308(13.54)$ & \\
\hline No & 32073 (99.06) & $13602(95.90)$ & $1967(86.46)$ & $1647.76,<0.0001$ \\
\hline
\end{tabular}


Table 2 Suicide methods related to violent and non-violent criminality

\begin{tabular}{|c|c|c|}
\hline Methods of suicide & Crime & $\mathrm{HR}, 95 \% \mathrm{Cl}$ \\
\hline \multirow[t]{3}{*}{ Poisoning ( $n=278)$ : E950-E952, E980-E982, X60-X69, Y10-Y19 } & No crime & 1.0 \\
\hline & Non-violent crime & $2.94,2.26$ to 3.81 \\
\hline & Violent crime & $6.92,4.91$ to 9.76 \\
\hline \multirow[t]{3}{*}{ Hanging/suffocation ( $n=149)$ : E953, E983, X70, Y20 } & No crime & 1.0 \\
\hline & Non-violent crime & $1.28,0.90$ to 1.83 \\
\hline & Violent crime & $2.54,1.47$ to 4.40 \\
\hline \multirow[t]{3}{*}{ Firearm ( $n=69)$ : E955, E985, X72-X74, Y22-Y24 } & No crime & 1.0 \\
\hline & Non-violent crime & $1.39,0.83$ to 2.34 \\
\hline & Violent crime & $3.08,1.44$ to 6.60 \\
\hline \multirow[t]{3}{*}{ Drowning $(n=41)$ : E954, E984, X71, Y21 } & No crime & 1.0 \\
\hline & Non-violent crime & $1.62,0.82$ to 3.20 \\
\hline & Violent crime & $5.17,2.19$ to 12.24 \\
\hline \multirow[t]{3}{*}{ Jump from heights ( $n=27)$ : E957, E987, X80, Y30 } & No crime & 1.0 \\
\hline & Non-violent crime & $3.23,1.43$ to 7.26 \\
\hline & Violent crime & $4.41,1.21$ to 16.00 \\
\hline \multirow[t]{3}{*}{ Moving train $(n=22)$ : E9580, E9880, X81, Y31 } & No crime & 1.0 \\
\hline & Non-violent crime & $2.07,0.84$ to 5.10 \\
\hline & Violent crime & $4.40,1.21$ to 15.98 \\
\hline \multirow[t]{3}{*}{ Cutting $(n=16)$ : E956, E986, X79, Y28 } & No crime & 1.0 \\
\hline & Non-violent crime & $4.61,1.58$ to 13.50 \\
\hline & Violent crime & $2.95,0.35$ to 25.23 \\
\hline Others ( $n=13)$ : E958-959, E988-989, X75-X77, X79, & No crime & 1.0 \\
\hline \multirow[t]{2}{*}{$\mathrm{X} 82-\mathrm{X} 84, \mathrm{Y} 22-\mathrm{Y} 24, \mathrm{Y} 29, \mathrm{Y} 32-\mathrm{Y} 34$} & Non-violent crime & $2.32,0.67$ to 8.01 \\
\hline & Violent crime & $8.99,2.15$ to 37.63 \\
\hline
\end{tabular}

criminals. All risk factors differed significantly $(p<0.0001)$ between the groups, but mostly prior contact with the police or juvenile authorities, and having had conducted problems at school. Regarding hospitalisation of alcohol or drug misuse which had occurred during the follow-up period, alcohol misuse differed most significantly between the groups.

\section{Methods of suicide}

Poisoning was the most prevalent method of suicide $(n=278)$ followed by hanging and suffocation $(n=149$; table 2). The violent offenders had nearly seven times higher hazard to die from poisoning $(\mathrm{HR}=6.92,95 \% \mathrm{CI}$ 4.91 to 9.76 ), while the non-violent criminal group had almost three times higher risk $(\mathrm{HR}=2.94,95 \%$ CI 2.26 to 3.81). The violent group had three times higher HR to die due to shooting by the firearm, while the non-violent group had no significant risk.

\section{Crude and multivariate analyses}

Violent-related criminality had the highest HR for suicide $(\mathrm{HR}=4.69,95 \%$ CI 3.56 to 6.19$)$ followed by nonviolent criminality $(\mathrm{HR}=2.08,95 \%$ CI 1.72 to 2.52$)$ in bivariate analyses. After adjustment for multiple confounders, the HRs decreased to nearly threefold $(\mathrm{HR}=2.68)$ and twofold $(\mathrm{HR}=1.65)$ (table 3$)$. Four of the 11 confounders in the model, for example, low emotional control $(\mathrm{HR}=1.4)$, low intellectual capacity (1.36), own medication for psychiatric problems $(\mathrm{HR}=1.40)$, and medication for nervous problem in the family $(\mathrm{HR}=1.23)$ were significantly associated with suicide. In the fully adjusted model, we also included alcohol and

Table 3 Criminality in relation to suicide adjusted for early risk factors measured at conscription* and in addition adjusted for alcohol and drug inpatient and suicide attempt†

\begin{tabular}{llllll}
\hline \multicolumn{7}{c}{ Suicide $\mathbf{N}=\mathbf{6 1 5}$} \\
\hline Criminality & Number of exposed & Number of cases & HR crude & HR adjusted* & HR adjusted \\
\hline Never & 32376 & 275 & 1.0 & 1.0 & 1.0 \\
Non-violent & 14183 & 252 & $2.08,1.72$ to 2.52 & $1.65,1.35$ to 2.01 & $1.35,1.10$ to 1.67 \\
Violent & 2275 & 88 & $4.69,3.56$ to 6.19 & $2.68,1.98$ to 3.64 & $1.30,0.92$ to 1.82 \\
\hline *Adjusted for fathers' social class, medication for nervous problems in the family, conduct problems at school, own medication for psychiatric \\
disorder, contact with police and juvenile authorities, emotional control, intellectual capacity, psychiatric diagnosis at conscription, sniffing of \\
solvents, risky alcohol misuse and substance misuse.
\end{tabular}


Table 4 Violent and non-violent offences and suicide

\begin{tabular}{|c|c|c|c|}
\hline \multicolumn{4}{|c|}{ Suicide $N=615$} \\
\hline Criminality & HR crude & HR adjusted* & HR adjusted† \\
\hline \multicolumn{4}{|l|}{ Non-violent offence } \\
\hline 0 offence $(n=32742,67.05 \%)$ & 1.0 & 1.0 & 1.0 \\
\hline 1 offence $(n=7315,14.98 \%)$ & $1.40,1.11$ to 1.78 & $1.15,0.88$ to 1.49 & $1.09,0.83$ to 1.41 \\
\hline $2+$ offences $(n=8777,17.97 \%)$ & $3.24,2.73$ to 3.85 & $2.17,1.76$ to 2.66 & $1.46,1.16$ to 1.83 \\
\hline \multicolumn{4}{|l|}{ Violent offence } \\
\hline 0 offence $(n=46559,95.34 \%)$ & 1.0 & 1.0 & 1.0 \\
\hline 1 offence $(n=1556,3.19 \%)$ & $2.65,1.96$ to 3.58 & $1.83,1.29$ to 2.59 & $1.17,0.82$ to 1.67 \\
\hline $2+$ offence $(n=719,1.47 \%)$ & $5.40,3.94$ to 7.39 & $2.42,1.61$ to 2.59 & $0.84,0.54$ to 1.31 \\
\hline \multicolumn{4}{|c|}{$\begin{array}{l}\text { Bivariate and multivariate Cox proportional regression analyses. } \\
\text { *Adjusted for fathers' social class, medication for nervous problems in the family, conduct problems at school, own medication for psychiatric } \\
\text { disorder, contact with police and juvenile authorities, emotional control, intellectual capacity, psychiatric diagnosis at conscription, sniffing of } \\
\text { solvents, risky alcohol misuse and substance misuse. } \\
\text { tln addition, adjusted for alcohol and drug inpatient and suicide attempt. }\end{array}$} \\
\hline
\end{tabular}

drug inpatient care stays and suicide attempt and found elevated HRs, however, only significant in non-violent offenders $(\mathrm{HR}=1.35$, 95\% CI 1.10 to 1.67). All these three inpatient care variables were associated with suicide: suicide attempt carried a hazard of 4.83 , while alcohol and drug misuse had lower hazards (2.00 and 1.74 , respectively).

\section{Repeated violent and non-violent offenders in relation to suicide}

The repeated non-violent and violent offences were associated with elevated HRs of suicide in the crude analyses $(\mathrm{HR}=3.24$ and $\mathrm{HR}=5.40)$. When adjusted for early confounders, the repeaters of violent and non-violent offences decreased to $\mathrm{HRs}=2.17$ and 2.42, respectively (table 4).

We conducted Kaplan-Meier survival distribution curves for the three criminal groups in relation to suicide from 1970 to 2004 . We found that violent criminality was associated with lower survival (figure 1).

\section{DISCUSSION}

One aim of this study was to analyse the association between male violent and non-violent offending and risk for suicide in a population-based cohort during a 35-year follow-up.

A main finding was that nearly one-third of the death cases were due to suicide in those who had ever committed a violent offence and one-fourth in the non-violent group. This is in line with earlier studies reporting high proportionate mortality among homicide offenders and among personality-disordered offenders participant to forensic psychiatric assessment. ${ }^{29-31}$

Another main finding was that violent offenders had nearly five times higher crude risk and non-violent offenders had more than twofold higher risk for suicide compared with non-criminals. Even after controlling for multiple confounders measured at conscription, HRs remained significant. Alcohol and substance misuse and attempted suicide in the fully adjusted model were confounding on suicide and only association between nonviolent offending and suicide remained significant. This implies a strong association between these clinical predictors and suicide risk. ${ }^{12} 32$ However, we do not have knowledge about the time order between criminality and the clinical factors measured during the follow-up period, hence we have to take the results with caution.

There is some evidence in the literature that violent criminals have higher rates of suicide, but these numbers are often derived from prison populations with often difficult circumstances such as overcrowded cells and spaces. ${ }^{33}$ Very few earlier studies on the association between violent and non-violent criminality and suicide have been conducted in a cohort representing the general population and with a long follow-up period. However, national data from England and Wales found after age standardisation, 9 to 13-fold increased risk for suicide in the prisoners and non-custody offenders. ${ }^{33}$

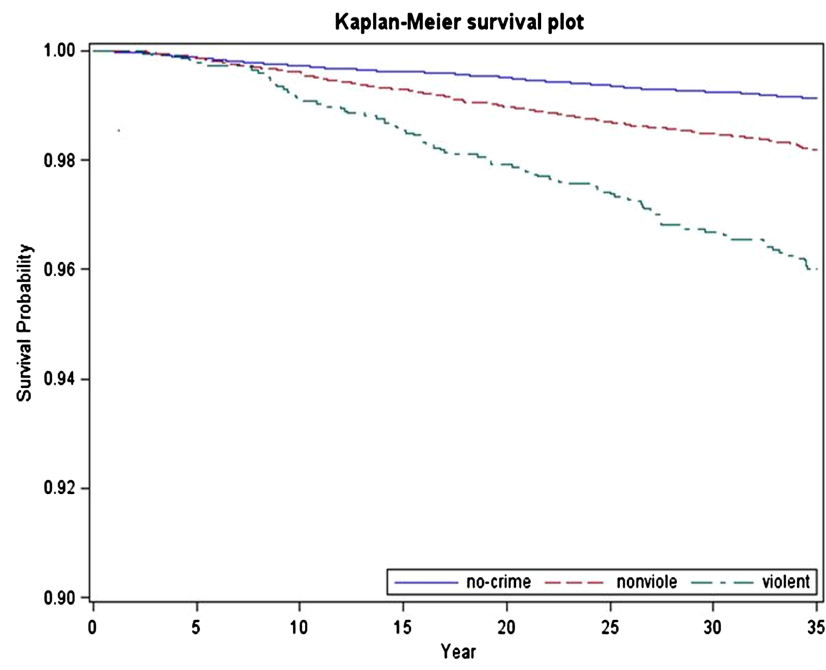

Figure 1 Kaplan-Meier survival plot for suicide in violent and non-violent criminals. 
We found that the suicide cases were rather equally distributed throughout the 35-year follow-up period which probably means that all age categories seem to be vulnerable to suicide. Other studies have shown that the yearly incidence rates of suicide have not clearly decreased in the younger age categories in Sweden, and that is why it is important to identify delinquency at young ages and other risk factors in order to find preventive strategies for this group. ${ }^{6}$ Generally, suicide rates are higher among the older age groups, often due to loneliness, anxiety disorder and depression. ${ }^{3435}$

Another finding was that poisoning as method of completed suicide was most prevalent in violent and nonviolent criminals, while hanging was the most prevalent method among non-criminals. That was also the case for men in the whole of Sweden. ${ }^{36}$ In a Danish national register study of 9708 suicide cases and 188134 agematched and gender-matched living controls, hanging and poisoning were the leading suicide methods among men and women,respectively. ${ }^{37}$ One possible explanation to the high prevalence of poisoning in criminals in our study could be that alcohol and substance use was more prevalent in the criminal groups including fatal and non-fatal poisonings compared with non-criminals.

\section{Suicide attempt and alcohol misuse}

We found that one-third of the violent offenders were already diagnosed at conscription with a psychiatric diagnosis. Psychiatric disorders are strongly related to suicide risk, whereas the association between mental illness and violent crime is not as evident. King and Barraclough ${ }^{39}$ found 27 times higher risk of unnatural death (suicide, accident and undetermined) among individuals who had recently been in contact with psychiatric clinics compared with those who had not. Persons with severe psychiatric disorders such as affective disorder and schizophrenia have highly elevated lifetime suicide risk. ${ }^{40} 41$

One of five suicide victims in this study had attempted suicide, confirming a strong association between suicide attempt and suicide. This was especially evident for violent offenders where 1 in 3 had attempted suicide. Suicide attempt has been considered as one of the strongest predictors of suicide and the risk seems to be elevated up to older ages and during long-time periods. ${ }^{42}$ In the total cohort, we found that 1192 men $(2.4 \%)$ had attempted suicide which could be considered as rather low frequency when compared with the suicides $(\mathrm{n}=615)$. An American national study (National Survey on Drug Use and Health), based on interviews and webquestionnaires from 92264 respondents in the years 2008 and 2009, found 1 suicide case for every 25 attempted suicides. ${ }^{43}$ We had data on only suicide attempts needing inpatient care, namely serious suicide attempts, which could explain the ratio. We did not have data on attempted suicides that not turn up as hospital records. Some suicide attempters do not search help at any care givers. ${ }^{44} 45$
In the present study, about half of the violent offenders had reported either risky alcohol or substance use at the time of conscription and nearly one-third of the violent offenders had been treated at hospital for an alcohol-related diagnosis. Alcohol misuse has also been pointed out as an important risk factor for suicide and in some studies the second most common diagnostic group. ${ }^{34}{ }^{46}$ Wilcox $e t ~ a l^{17}$ found alcohol misusers having a 10-fold increased risk for suicide in a mixed-age cohort. Likewise, in a longitudinal cohort study by Flensborg-Madsen et al, ${ }^{46}$ individuals with alcohol use disorders had eight times higher HRs of suicide compared with individuals with no alcohol use. The HR fell to three after adjustment of psychiatric disorders. These findings indicate the importance of early detection and prevention strategies and the treatment for substance users and especially those with suicidal tendencies in all ages. ${ }^{35}$ The relationship between alcohol use and violence seems to be complex. ${ }^{47}$ With the fact that the suicide rate is somewhat higher in violent criminals than in non-violent criminals, one could assume that alcohol misuse plays an important role for violence and suicide. ${ }^{46}$

\section{Advantages and limitations}

An advantage of this study is the large national cohort with a longitudinal design and with several adolescent confounders. Only a small part, $2-3 \%$ of the conscripts, was excluded from the study mainly because of physical or psychiatric disorders. The two questionnaires used at conscription were non-anonymous, which could have contributed to a lower response rate of especially problematic issues such as alcohol and substance use. However, other studies on conscription cohort have compared register and self-reported information about alcohol and substance use and found a good agreement between the different sources of data. ${ }^{25} \mathrm{~A}$ small number of the conscripts missed one or some of the items in the questionnaires. That was especially evident for those participants who had committed violent offences whereas the response rate for the confounders included in the study varied from $0.26 \%$ to $9.45 \%$. The corresponding measures for other criminality and non-criminals were $0.20-6.37 \%$ and $0.13-4.19 \%$, respectively. The violent offenders had probably more severe risk factors than the non-violent and non-criminal groups which could have resulted in underestimating of the HRs of suicide. One could assume that these participants also had higher rates of substance use and other maladjusted behaviour measured at conscription which in turn could have affected the outcome. ${ }^{48}$ However, we have no reason to believe that the risk for the outcome, suicide, has been considerably affected due the internal missing data.

Another limitation of this study is that we do not have information about criminality not turning up in the register. Some participants could have committed many violent and non-violent crimes, especially in combination with substance misuse, and never been convicted of a crime. 


\section{CONCLUSIONS}

We found that individuals registered for either violent or other criminality are at an increased risk for committing suicide and that is especially evident for those who were criminal repeaters. However, after adjusting for confounders measured at conscription, the risk was still elevated and just slightly significant or non-significant in the fully adjusted model including hospitalisation due to alcohol and substance misuse and suicide attempt. The two criminal groups were more likely to use poisoning as the suicide method, indicating prior experiences of substance misuse. Hanging was most prevalent in the noncriminal group which is in line with the general population in Sweden. ${ }^{36}$ We suggest that authorities and the healthcare should observe the increased risk for suicide in violent and non-violent criminals, especially those with earlier suicide attempt and comorbid alcohol and substance misuse.

Acknowledgements The authors would like to thank statistician Anders Leifman for the valuable statistical advice.

Contributors MS planned the study, conducted the statistical analyses and wrote the final version of the manuscript. JJ and AR contributed to the planning of the study and preparing of the manuscript. All the authors contributed to the final draft of the manuscript.

Funding The research for this study was supported by Co-ordination of the Swedish Drug Policy (Dnr 238/2006:18), by the Swedish Research Council (Project numbers: K2009-61P-21304-04-4; K2009-61X-21305-01-1) and through the regional agreement on medical training and clinical research (ALF) between Stockholm County Council and Karolinska Institutet, Stockholm Centre for Psychiatric Research and Education.

Competing interests None.

Ethics approval Regional ethical review board in Stockholm (Dnr 2007/ 174-31, Dnr 2008/1086-31/5).

Provenance and peer review Not commissioned; externally peer reviewed.

Data sharing statement No additional data are available.

Open Access This is an Open Access article distributed in accordance with the Creative Commons Attribution Non Commercial (CC BY-NC 3.0) license, which permits others to distribute, remix, adapt, build upon this work noncommercially, and license their derivative works on different terms, provided the original work is properly cited and the use is non-commercial. See: http:// creativecommons.org/licenses/by-nc/3.0/

\section{REFERENCES}

1. World Health Organization. World suicide prevention day 2012. http://www.who.int/mediacentre/events/annual/world suicide prevention day/en/

2. Bertolote JM, Fleischmann A. A global perspective on the magnitude of suicide mortality. In: Wasserman D, Wasserman C. eds Oxfbord textbook of suicidology and suicide prevention: a global perspective. Oxford: Oxford University Press, 2009:91-8.

3. Patton GC, Coffey C, Sawyer SM, et al. Global patterns of mortality in young people: a systematic analysis of population health data. Lancet 2009;374:881-92.

4. Karimina A, Law MG, Butler TG, et al. Suicide risk among recently released prisoners in New South Wales, Australia. Med J Aust 2007:18:387-90.

5. Fazel S, Benning R, Danesh J. Suicides in male prisoners in England and Wales, 1978-2003. Lancet 2005;366:1301-2.

6. Webb R, Qin P, Stevens H. National study of suicide in all people with a criminal justice history. Arch Gen Psychiatr 2011;68:591-9.

7. Hayes LM. National study of jail suicides: seven year later. Psychiatr Q 1989;60:7-29.
8. Boardman AP, Grimbaldeston AH, Handley C, et al. The North Staffordshire Suicide Study: a case-control study of suicide in one health district. Psychol Med 1999;29:27-33.

9. Linsley KR, Johnson N, Martin J. Police contact within 3 months of suicide and associated health service contact. Br J Psychiatry 2007;190:170-1.

10. Björkenstam E, Björkenstam C, Vinnerljung B, et al. Juvenile delinquency, social background-a Swedish national cohort study of 992881 young adults. Int J Epidemiol 2011;40:1585-92.

11. Harris EC, Barraclough B. Suicide as an outcome for mental disorders. A meta-analysis. Br J Psychiatry 1997;170:205-28.

12. Tidemalm $\mathrm{D}$, Långström $\mathrm{N}$, Lichtenstein $\mathrm{P}$, et al. Risk of suicide after suicide attempt according to coexisting psychiatric disorder: Swedish cohort study with long term follow-up. BMJ 2008;337: a2205.

13. Runeson B, Tidemalm D, Dahlin M, et al. Method of attempted suicide as predictor of subsequent successful suicide: national long term cohort study. BMJ 2010;340:c3222.

14. Stenbacka M, Moberg T, Romelsjö A, et al. Mortality and causes of death among violent offenders and victims - a Swedish population based longitudinal study. BMC Public Health 2012;12:1-10.

15. Darke S, Douflou J, Torok M. Toxicology and circumstances of completed suicide by means other than overdose. J Forensic Sci 2009;54:490-4.

16. Darke S, Duflou J, Totok M. Toxicology and characteristics of fatal oxycodone toxicity cases in New South Wales, Australia 1999-2008. $\checkmark$ Forensic Sci 2011;56:690-3.

17. Wilcox HC, Conner KR, Caine ED. Association of alcohol and drug use disorders and completed suicide: an empirical review of cohort studies. Drug Alc Depend 2004;7:11-19.

18. Allebeck P, Allgulander C, Fisher LD. Predictors of completed suicide in a cohort of 50465 young men: role of personality and deviant behaviour. BMJ 1988;297:176-8.

19. Andreasson S, Allebeck P, Romelsjo A. Alcohol and mortality among young men. Longitudinal study of Swedish conscripts. $B M J$ 1988;296:1021-5.

20. Eriksson A, Romelsjö A, Stenbacka M, et al. Early risk factors for criminal offending in schizophrenia: a 35-year longitudinal cohort study. Soc Psychiatr Epidemiol 2011;46:925-32.

21. Stenbacka M, Leifman L, Dalal K, et al. Early predictors of injury mortality among Swedish conscripts: a 35-year follow-up study. Accid Anal Prev 2011;43:228-34.

22. Davstad I, Allebeck P, Leifman A, et al. Self-reported drug use and mortality among a nationwide sample of Swedish conscripts-a 35-year follow-up. Drug Alc Depend 2011;118:383-90.

23. Uppmark M, Karlsson G, Romelsjö A. Drink driving and criminal behaviours as risk factors for receipt of disability pension and sick leave: a prospective study of young men. Addiction 1999;94:507-19.

24. Otto U; Male youths. A sociopsychiatric study of a total annual population of Swedish adolescent boys. Acta Psychiatr Scand 1976; (Suppl 264):1-312.

25. Benson $\mathrm{G}$, Holmberg MB. Validity of questionnaire in population studies on drug use. Acta Psychiatr Scand 1985;70:9-18.

26. Rydelius P-A. Alcohol-abusing teenage boys. Acta Psychiatr Scand 1983;68:368-80.

27. Ståhlberg B. I-provet (intelligence test: the Swedish enlistment battery). Karlstad: Militärpsykologiska Institutet, 1971 (In Swedish).

28. David AS, Malmberg L, Brandt L, et al. IQ and risk for schizophrenia: a population-based cohort study. Psychol Med 1997;27:1311-23.

29. Kullgren G, Tengström A, Grann M. Suicide among personality-disordered offenders: a follow-up study of 1943 male criminal offenders. Psychiatr Epidemiol 1998;33:102-6.

30. Jokinen J, Forslund K, Nordström AL, et al. Suicide risk after homicide in Sweden. Arch Suicide Res 2009;13:297-301.

31. Jokinen J, Forslund K, Ahnemark E, et al. Karolinska interpersonal violence scale predicts suicide in suicide attempters. J Clin Psychiatry 2010;71:1025-32.

32. Waern M. Risk factors for suicide in the elderly: what do we know? What do we need to find out? Suicidologi 2011;16:3-8.

33. Sattar G. Rates and causes of death among prisoners and offenders under community supervision. Home Office Research Study, London Home Office, 2001:231.

34. Waern M. Alcohol dependence and abuse in elderly suicides. Alcohol and Alcohol 2003;38:249-54.

35. Whiteford HA, Degenhardt L, Rehm J, et al. Global burden of disease attributable to mental and substance use disorders: findings from the Global Burden of Disease Study 2010. Lancet 2013;382:1575-86

36. National Board on Health and Welfare, The Cause of Death Register, 2012. 
37. Webb RT, Qin P, Stevens H, et al. National study of suicide method in violent criminal offenders. J Affect Disord 2013;150:237-44.

38. Titelman $\mathrm{D}$, Oskarsson $\mathrm{H}$, Wahlbeck $\mathrm{K}$, et al. Suicide mortality trends in the Nordic countries 1980-2009. Nord J Psychiatry 2013;67:414-23.

39. King $E$, Barraclough B. Violent death and mental illness: a study of a single catchment area over eight years. Br J Psychiatry 1990;156:714-20.

40. Carlborg A, Winnerbäck K, Jönson EG, et al. Suicide in schizophrenia. Expert Rev Neurother 2010;10:1153-64.

41. Nordentoft M, Mortensen PB, Pedersen CB. Absolute risk of suicide after first hospital contact in mental disorder. Arch Gen Psychiatry 2011;68:1058-64.

42. Suominen $\mathrm{K}$, Isometsa $\mathrm{E}$, Suokas $\mathrm{J}$, et al. Completed suicide after a suicide attempt: a 37-year follow-up study. Am J Psychiatry 2004:161:562-3.

43. Crosby AE, Han B, Ortega LAG, et al. Suicidal thoughts and behaviors among adults aged $>18$ years-United States, 2008-2009. MMWR Surveill Summ 2011;60:1-22.(no. SS-13).
44. Guilherme B, Jules A, Nock MK, et al. Risk factors for twelve-month suicide attempts in the National Comorbidity Survey Replication (NCS-R). Psychol Med 2006;36:1747-57.

45. De Leo D, Ester C, Kym S, et al. Lifetime risk of suicide ideation and attempts in an Australian community: prevalence, suicidal process, and help-seeking behaviour. J Affect Disord 2005;86:215-24.

46. Flensborg-Madsen T, Knop J, Mortensen EL, et al. Alcohol use disorders increase the risk of completed suicide-irrespective of other psychiatric disorders. A longitudinal cohort study. Psychiatry Res 2009;167:123-30.

47. Lipsey MW, Wilson DB, Cohen MA, et al. Is there a causal relationship between alcohol use and violence? A synthesis of evidence. Recent Dev Alcohol 1997;13:245-82.

48. Stattin H, Romelsjö R, Stenbacka M. Personal resources as modifiers of the risk for future criminality: an analysis of protective factors in relation to 18-year-old boys. Br J Criminol 1997;37:198-223. 